\title{
富磷型贵金属磷化物的绿色制备及电催化
}

孙学良

加拿大西安大略大学机械与材料工程系, 安大略省 N6A 3K7, 加拿大

\section{Green Synthesis and Electrocatalysis of P-Rich Noble Metal Phosphides}

\section{Xueliang Sun}

Department of Mechanical and Materials Engineering, University of Western Ontario, 1151 Richmond St, London, Ontario, N6A 3K7, Canada.

Email: xsun9@uwo.ca

Published online: December 8, 2020.

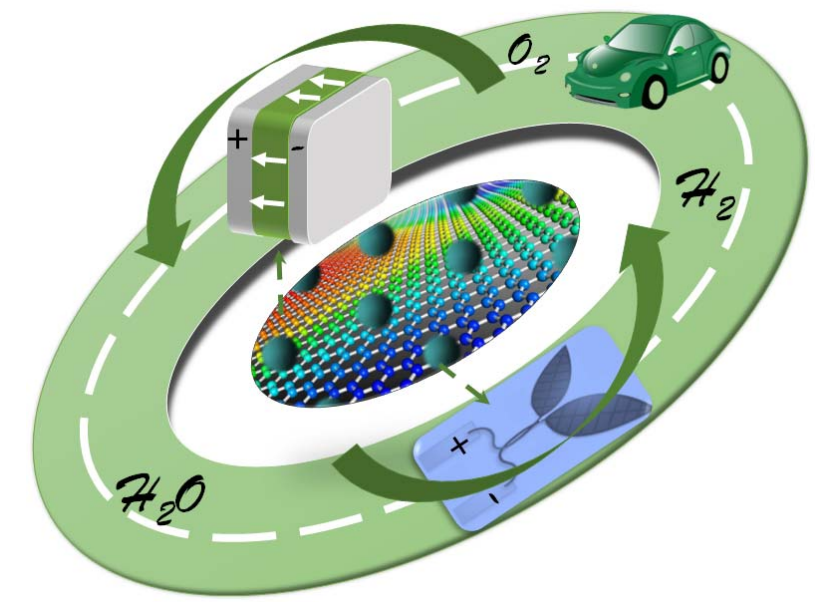

过渡金属磷化物的催化应用——氢从水中来, 还到水中去。

过渡金属磷化物(TMPs), 由于具有独特的物 理化学性质, 在电解水、燃料电池、金属空气电池 等能源电催化领域展现出极大的应用潜力。理论 研究表明, 由于磷 $(\mathrm{P})$ 原子半径较大, $\mathrm{P}$ 的引入使金 属原子间距相对增加, 原子间相互作用减弱, 导致 金属 $\mathrm{d}$ 带收缩, 费米能级附近态密度增加 ${ }^{1,2}$ 。因此, 这类化合物可具有优异的本征催化活性。与此同 时, $\mathrm{P}$ 原子由于电负性较大容易吸引金属电子而带 负电, 进而可作为催化活性位点捕获带正电的质 子 $^{3}$ 。因此, 提高TMPs中P的含量可成为改善电解 水制氢性能的一种有效途径。更重要的是, 对于贵 金属(如Pt族金属)磷化物, 增加其中的P含量, 可以 减少贵金属剂量, 进而降低催化剂成本。然而, TMPs的导电性通常会随着P含量的增加而降低 ${ }^{4}$ 。
而且, 富磷型TMPs具有熔点低、热稳定性差等缺 点, 使得大多数富磷型TMPs 难以可控合成 5 。另一 方面, 富磷型TMPs表面易被氧化, 导致合成此类 化合物相对比较困难。因此, 如何在绿色、温和条 件下实现富磷型贵金属磷化物的可控制备已成为 当前一大挑战, 急需探索一种简单、通用且高效的 富磷型贵金属磷化物催化材料的合成方法。

武汉理工大学木士春教授课题组借助绿色的 植酸为磷源, 在适度温压下, 利用㲵胺类加热释放 的还原性气氛首次可控合成出了一系列富磷型贵 金属磷化物, 包括 $\mathrm{RuP}_{2} 、 \mathrm{PtP}_{2} 、 \mathrm{IrP}_{2} 、 \mathrm{RhP}_{2} 、 \mathrm{Pd}_{5} \mathrm{P}_{2}$ 等 ${ }^{6-10}$, 面且这些富磷型贵金属磷化物的表面被多 孔少层的 $\mathrm{N} 、 \mathrm{P}$ 掺杂薄碳所封装, 有利于提高催化 剂的导电性和电化学稳定性。经强酸、中性、强碱 
条件下的水电解制氢实验表明, 所获得富磷型贵 金属磷化物绝大部分表现出与商业铂碳 (20\% $\mathrm{Pt} / \mathrm{C}$ )催化剂相媲美的析氢反应(HER)催化活性和 高的电化学稳定性。因此, 这种独特的复合纳米结 构可促进富磷型过渡金属磷化物的导电性、催化 活性及稳定性的大幅度提升。

除了具有类铂的HER催化活性, 上述一些富 磷型贵金属磷化物催化材料还展现出类铂的氢氧 化反应(HOR)及氧还原反应(ORR)等催化活性。如 所得到的 $\mathrm{PtP}_{2}$ 和 $\mathrm{IrP}_{2}$ 均展现出高于商业铂碳的 $\mathrm{HOR}$ 质量活性 6,7,10。同时, 低铂含量的 $\mathrm{PtP}_{2} @ \mathrm{PNC}$ 催化剂在碱性溶液中表现出高于商业铂碳的ORR 质量活性, 而在酸性溶液中也展现出与商业铂碳 可比的ORR活性 ${ }^{6}$ 。无疑, 这类催化材料已具备了 从电解水制氢到氢燃料电池发电的多功能催化应 用, 为实现 “氢从水中来, 还到水中去” 的绿色循 环理念提供了保障。

上述相关研究成果已于近期分别在iScience, Angewandte Chemie-International Edition, Energy \& Environmental Science, Advanced Functional Materials, Journal of Catalysis等期刊上发表。这 些成果的取得对开发新型廉价、高活性和长寿命 的过渡金属磷化物体系催化剂具有重要的科学指 导意义。同时, 也为实现富磷型磷化物的可控合成 及规模化应用奠定了基础。

\section{References}

(1) Gao, R.; Pan, L.; Wang, H.; Zhang, X.; Wang, L.; Zou, J. ACS Catal. 2018, 8, 8420. doi: 10.1021/acscatal.8b02091

(2) Liu, P.; Rodriguez, J. A.Catal. Lett. 2003, 91, 247. doi: 10.1023/B:CATL.0000007163.01772.19

(3) Cai, J.; Song, Y.; Zang, Y.; Niu, S.; Wu, Y.; Xie, Y.; Zheng, X.; Liu, Y.; Lin, Y.; Liu, X.; Wang, G.; Qian, Y. Sci. Adv. 2020, 6, eaaw8113. doi: $10.1126 /$ sciadv.aaw8113

(4) Shi, Y.; Zhang, B. Chem. Soc. Rev. 2016, 45, 1529. doi: 10.1039/C5CS00434A

(5) Liu, Z.; Yang, S.; Sun, B.; Yang P.; Zheng, J.; Li, X. Angew. Chem. Int. Ed. 2020, 132, 1991. doi: 10.1002/ange.201910474

(6) Pu, Z.; Cheng, R.; Zhao, J.; Hu, Z.; Li, C.; Li, W.; Wang, P.; Amiinu, I. S.; Wang, Z.; Wang, M.; Chen, D.; Mu, S. iScience 2020, 23, 101793. doi: $10.1016 /$ j.isci.2020.101793

(7) Pu, Z.; Zhao, J.; Amiinu, I. S.; Li, W.; Wang, M.; He, D.; Mu, S. Energy Environ. Sci. 2019, 12, 952. doi: 10.1039/C9EE00197B

(8) Pu, Z.; Amiinu, I. S.; Kou, Z.; Li, W.; Mu, S. Angew. Chem. Int. Ed. 2017, 56, 11559. doi: 10.1002/anie.201704911

(9) Pu, Z., Liu, T.; Amiinu, I. S.; Cheng, R.; Wang, P.; Zhang, C.; Ji, P.; Hu, W.; Liu J.; Mu, S. Adv.Funct. Mater. 2020, 30, 2004009. doi: 10.1002/adfm.202004009

(10) Zhao, J.; Pu, Z.;Jin, H.; Zhang, Z.; Liu, J.; Mu, S. J. Catal. 2020, 383, 244. doi: 10.1016/j.jcat.2020.01.026 